\title{
KESIAPAN DIGITALISASI LAYANAN \\ SISTEM PEMERINTAHAN BERBASIS ELEKTRONIK PADA \\ BADAN PENGKAJIAN DAN PENERAPAN TEKNOLOGI (BPPT)
}

\section{READINESS OF DIGITALIZATION SERVICES FOR ELECTRONIC-BASED GOVERNMENT SYSTEMS IN AGENCY FOR THE ASSESSMENT AND APPLICATION OF TECHNOLOGY (BPPT)}

\section{Pinggar Hawa* \\ Roy Valiant Salomo}

*Fakultas Ilmu Administrasi, Universitas Indonesia, Jakarta, Indonesia

*email:

pinggar hawa@yahoo.com

\section{Kata Kunci:}

SPBE

Kesiapan

Perkantoran Elektronik

Digitalisasi Layanan

Keywords:

E-government

Readiness

E-office

Service Digitalization

\section{Accepted}

Februari 2020

Published

April 2020

\begin{abstract}
Abstrak
E-Government di Indonesia bukanlah suatu hal yang baru karena Pemerintah Indonesia sudah membakukan e-Government dengan istilah Sistem Pemerintahan Berbasis Elektronik yang bertujuan meningkatkan kualitas layanan publik dengan efektif serta efisien. Penelitian ini diharapkan dapat menganalisa Kesiapan Badan Pengkajian dan Penerapan Teknologi (BPPT) dalam melaksanakan perubahan yang cukup besar yaitu implementasi Sistem Pemerintahan Berbasis Elektronik dengan dilahirkannya 4I aplikasi digitalisasi layanan administrasi, dan upaya-upaya yang dilakukan agar transformasi digital berjalan dengan baik, guna mendapatkan hasil penulis menggunakan metode post-positivism dengan pendekatan analisis deskriptif yang didapat melalui wawancara mendalam terhadap empat dimensi Readiness to organizational change yang terdiri dari, Change Spesific efficacy, Appropriateness, Management support, serta Personal valence yang memberikan informasi kondisi bahwa Badan Pengkajian dan Penerapan Teknologi sudah memiliki kesiapan impelementasi Penerapan Digitalisasi layanan e-office namun belum ideal karena Sistem Pemerintahan Berbasis Elektronik yang direncanakan belum sepenuhnya terintegrasi, diterapkan dan diuji coba serta membutuhkan pengembangan lebih lanjut.
\end{abstract}

\begin{abstract}
E-Government in Indonesia is not something new, because the Indonesian government has standarized e-Government in terms of Electronic-Based Government Systems which aims to improve the quality of public services effectively and efficiently. This research is expected to present the readiness analysis of the Agency for the Assessment and Application of Technology (BPPT) in implementing significant changes which are the implementation of Electronic-Based Government Systems with the presence of 41 applications to digitizing administrative services, and the efforts made to perform a proper digital transformation. To achievieving a proper result, the author utilize the postpositivism method with a descriptive analysis approach which obtained through in-depth interviews of the four dimensions of Readiness to organizational change that consist of Change Specific efficacy, Appropriateness, Management support, and Personal Valence. These dimensions will provides information regarding the readiness conditions of Agency for the Assessment and Application of Technology to implement the Digitalization of eoffice which are ready but not in ideal condition because the planned Electronic-Based Government System is still not fully integrated, implemented and tested which requires further development.
\end{abstract} DOI: https://doi.org//0.33084/restorica.v5i2

\section{PENDAHULUAN}

Teknologi informasi dan komunikasi yang digunakan dalam lingkungan pemerintahan dengan tujuan meningkatkan kualitas layanan publik dengan efektif serta efisien disebut dengan istilah
e-Government. Saat ini Pemerintah Indonesia telah mengeluarkan Peraturan Presiden RI Nomor 95 Tahun 2018 tentang Sistem Pemerintahan Berbasis Elektronik dimana perlu diketahui sejak terbentuknya Perpres tersebut kita harus menyamakan persepsi bahwa yang 
dimaksud e-Government adalah sama dengan Sistem Pemerintah Berbasis Elektronik (SPBE). Perpres tersebut mengatur Ketatalaksanaan SPBE, Manajemen SPBE, Audit Teknologi Informasi dan Komunikasi, Penerapan SPBE, percepatan SPBE, serta monitoring serta evaluasi SPBE. Badan Pengkajian dan Penerapan Teknologi (BPPT) sebagai salah satu Instansi Pemerintah diharapan turut menerapkan SPBE dengan mengikuti semua peraturan yang berlaku terkait SPBE. Untuk menerapkan SPBE didalam organisasinya, BPPT telah membuat aplikasi-aplikasi proses kerja yang dapat disebut sebagai elektronik office atau e-office. Pengembangan SPBE didalam organisasi BPPT sudah cukup lama dilakukan baik dalam bentuk aplikasi maupun infrastruktur jaringan dengan tujuan meningkatkan kualitas penyelenggaraan pemerintahan serta pelayanan kepada masyarakat dan juga untuk pelayanan secara internal BPPT itu sendiri. Akan tetapi masih banyak diperlukan perbaikan terhadap sistem yang SPBE tersebut karena pesatnya perkembangan teknologi serta tuntutan masyarakat terhadap pelayanan yang lebih efisien dan terbuka.

Penerapan e-office secara konsep sudah diatur dalam beberapa Undang-undang Negara Republik Indonesia dimana dalam hal ini Pemerintah memberi perhatian khusus terhadap pemerintahan berbasis elektronik, hal ini tercantum dalam Undang-Undang Nomor 14 Tahun 2008 tentang Keterbukaan Informasi Publik, Di dalam pasal 2 ayat I pada undang-undang tersebut tersebut mengandung arti bahwa informasi publik harus dapat diakses dengan cepat dan tepat waktu, dengan biaya ringan, dan dengan cara yang sederhana, hal ini sangat sejalan dengan sistem SPBE dimana sistem paperless office mendukung terciptanya keterbukaan tersebut. Serta yang terbaru adalah Peraturan Presiden RI Nomor 95 Tahun 2018 tentang Sistem Pemerintahan Berbasis Elektronik dimana perlu diketahui sejak terbentuknya Perpres tentang SPBE diatas kita harus sudah menyamakan persepsi bahwa yang dimaksud SPBE adalah sama dengan Sistem Pemerintah Berbasis Elektronik (SPBE).

Lembaga Pemerintah Non Kementerian yaitu Badan Pengkajian dan Penerapan Teknologi (BPPT) atau yang lebih dikenal dengan BPPT adalah Lembaga Pemerintah Non-Kementerian yang koordinasinya berada dibawah Kementerian Riset Teknologi / BRIN. Karena peran dan fungsinya yang sangat erat dengan inovasi dan perkembangan teknologi menjadi tantangan tersendiri bagi penulis untuk mendalami mengenai masalah yang terjadi pada suatu Lembaga Negara seperti BPPT saat ini sedang merencanakan penerapkan transformasi digital atau e-office secara keseluruhan dalam keadministrasian. Sebagai salah satu pionir di bidang pengkajian dan penerapan teknologi justru belum menerapkan konsep e-office sebagai bagian dari SPBE secara maksimal, untuk itu maka lingkup penelitian ini adalah terhadap kesiapan dari BPPT untuk berinovasi menuju digitalisasi e-office karena perubahan itu sangat sesuai dan dibutuhkan (appropriateness) pada sistem administrasi perkantoran di BPPT yang masih banyak menggunakan cetak manual, dan juga BPPT adalah lembaga yang berbasis pengkajian dan penerapan teknologi sudah seyogyanya harus menerapkan e-office secara baik.

Dalam kesehariannya saat ini BPPT masih banyak menggunakan sistem administrasi perkantoran dengan alat cetak kertas manual, sistem ini tentunya menggunakan persediaan kertas dan alat kantor yang cukup banyak sebagai bentuk pencetakan dan pengarsipan. Hal tersebut membutuhkan tenaga dan waktu yang tidak sedikit dalam proses pendistribusian atau pengiriman dokumen. Masalah lain yang timbul dalam sistem administrasi perkantoran manual yaitu dalam hal pengarsipan, mulai dari penyimpanan dokumen yang membutuhkan ruangan fisik yang tidak kecil di area kantor sehingga menyebabkan tumpukan rak dokumen-dokumen yang mengakibatkan berkurangnya ruang kantor yang seharusnya dapat 
dimanfaatkan untuk fungsi lainnya. Kemudian hal ini juga berpengaruh pada pencarian dokumen yang menjadi sulit ditemukan apabila dokumen tidak tersimpan dengan baik, rapih dan teratur, dan yang menjadi resiko paling mengkhawatirkan adalah kerusakan dokumen fisik yang mungkin terjasi terutama pada dokumen berusia lanjut. Dari berbagai hal tersebut diatas dapat dilihat BPPT belum memiliki kesiapan akan perubahan kearah e-office.

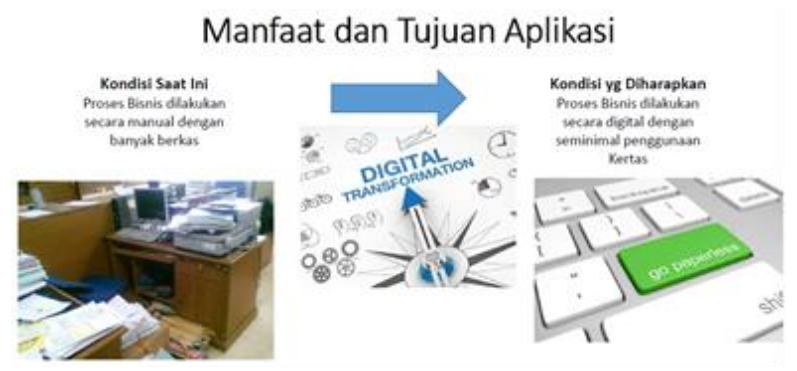

Gambar I : Manfaat dan Kondisi yang diinginkan

Tabel I. Efisiensi Biaya Menggunakan e-Arsip

\begin{tabular}{|l|c|}
\hline Jumlah Nota Dinas yang dibuat dan didistribusikan & 1.265 .704 \\
\hline Jumlah Surat Dinas yang dibuat dan didistribusikan & 144.665 \\
\hline Surat Dinas masuk yang diterima dan didistribusikan & 22.034 \\
\hline Total Nota surat masuk dan surat keluar & 1.432 .403 \\
\hline Rata-rata 1 nota/surat 5 lembar beserta lampiran & 7.162 .015 \\
\hline Asusi biaya kertas, cetak dan distribusi perlembar & 500 \\
\hline Biaya yang bisa di hemat kantor & Rp. 120.213 .852 \\
\hline
\end{tabular}

Sumber : Unit Kearsipan BPPT

Menyadari Kekurangannya pada tahun 2019 bertepatan dengan HUT BPPT ke 4I, BPPT melahirkan gebrakan Besar-besaran dengan melaunching 4I Aplikasi e-office sebagai transformasi digital terhadap layanan sistem administrasinya. Ide tersebut diinisiasi langsung dari Pimpinan Tertinggi BPPT yaitu Kepala BPPT yang artinya trasnformasi digital SPBE BPPT adalah salah satu fokus yang dituju dimana Hennessy (1998) menemukan bahwa "paket" kompetensi yang dimiliki oleh para pemimpin berkorelasi dengan tingkat perubahan budaya (Stewart \& Kringas, 2003). Jadi budaya organisasi yang kaku sebetulnya bisa berubah perlahan mengikuti arah dari pimpinan yang memiliki pandangan visioner. Kepemimpinan bukan hanya sebagai puncak hierarki, akan tetapi juga merupakan puncak pemikiran yang sederhana. Ini artinya dalam beberapa dekade kedepan kita akan melihat jenis organisasi baru yang muncul untuk mengatasi lingkungan yang bergerak dengan cepat serta lebih conmpetitive dengan jenis pegawai baru yang pasti bisa dilihat di organisasi yang sukses (Kotter, 1996 : 175). Sudah banyak tulisan mengenai kajian analisis kesiapan sumber daya manusia (SDM) guna menghadapi perubahan yaitu penggunaan SPBE, Akan tetapi penelitian terhadap isu kesiapan penerapan e-office dalam transformasi digital sistem administrasi di Instansi BPPT sendiri belum pernah dilakukan.

Telah ada penelitian terdahulu oleh Haddi Welfarendi (2016) yang menganalisa kesiapan implementasi administrasi perkantoran maya (siMaya) sebagai perwujudan e-Office pada Kementerian Pendayagunaan Aparatur Negara Dan Reformasi. Dalam tulisannya Haddi (2016) berfokus kepada analisa Kemenpan RB dari sisi inisiator kebijakan dalam implementasi program yang menjadi bagian dari SPBE. Hasil yang didapatkan adalah Implementasi siMaya yang dilakukan oleh Kemenpan RB masih memiliki banyak kendala diantaranya Perubahan Paradigma belum berjalan secara signifikan dan belum terlihat manfaat yang dirasakan dalam penggunaan, kemudian kompetensi Sumber Daya Manusia di Kemenpan RB belum merata dalam penggunaan IT, dan SDM belum memiliki kesadaran untuk memanfaatkan IT akibat rendahnya sosialisasi. Sedangkan kebaruan penelitian yang penulis lakukan di BPPT memiliki kondisi belum diterapkannya e-office serta aplikasi satu pintu yang terintegrasi untuk semua administrasi perkantoran masih dalam tahap pengembangan sistem administrasi dari manual ke digital.

Penelitian lainnya lim Ruchiyat (20/3) yang meneliti tentang implementasi e-Office pada Sekretariat Jenderal Kementerian Hukum Dan Ham RI yang bertujuan menganalisis penyelenggaraan e-Office pada unit Sekretariat Jenderal Kementerian Hukum Dan HAM. Penelitian tersebut menitik beratkan pada analisa terhadap hasil implementasi e-Office yang sudah 
di terapkan oleh Sek Jenderal Kementerian Hukum Dan HAM dalam operasional pekerjaan, hasil yang dikemukakan oleh Ruchiyat bahwa dapat dikatakan praktek e-Office pada unit Sek Jenderal Kementerian Hukum Dan HAM masih gagal, karena variabel komunikasi, sumber daya, sikap, struktur organisasi masih belum memiliki keterkaitan satu dengan yang lainnya. Lokus yang di teliti oleh Ruchiyat hanya terbatas pada lingkup satu bagian kecil dari suatu instansi, sedangkan lokus penulis mencakup kesluruhan dari instansi BPPT.

\section{Definition/ Literatur review}

SPBE secara umum dapat diartikan sebagai proses kegiatan program pemerintah yang menggunakan media teknologi informasi serta dilakukan oleh suatu organisasi pemerintah yang memiliki kapabilitas untuk mengubah hubungan pemerintah dengan warga Negara, bisnis dan lainnya, perpanjangan tangan pemerintah memiliki potensi untuk mengarah pada partisipasi dan keterlibatan masyarakat yang lebih baik (Evans \& Yen, 2006). Sedangkan menurut Stiglitz, et al, (2000) SPBE adalah salah satu cara bagi pemerintah dalam memanfaatkan teknologi baru untuk memberikan publik akses yang lebih mudah ke informasi dan layanan pemerintah, serta meningkatkan kualitas layanan dan memberikan peluang yang lebih besar untuk berpartisipasi dalam suatu lembaga dan juga berpartisipasi dalam proses demokrasi (Li \& Dai, 20II). Salah satu penerapan SPBE dalam pemerintahan yang mendukung kegiatan administrasi perkantoran adalah e-office.

Elektronic Office atau e-office adalah sebuah layanan aplikasi yang memberikan suatu konsep paperless guna meminimalisir penggunaan kertas dalam kegiatan administrasi perkantoran, surat-menyurat, korespondensi yang dapat digunakan oleh semua karyawan serta pejabat di suatu instansi atau perusahaan secara elektronik (Aziz, 2010). e-office itu sendiri adalah bagian utama dari SPBE, karakteristik dari e-office memiliki arti bahwa setiap pekerjaan kantor dapat dilakukan dimana pun selama tempat kerja itu terhubung dengan perusahaan melalui sejenis alat komunikasi berbasis sistem elektronik. Dengan adanya e-office di perkantoran atau instansi pemerintah diharapkan proses pelaksanaan kegiatan administrasi perkantoran dapat dilakukan dengan lebih mudah, cepat, transparan, akurat, aman, dan efisien.

Adapun Kesiapan elektronik atau e-readiness pada SPBE di BPPT, Dada (2006) mendefinisikan ereadiness sebagai ukuran sejauh mana suatu negara, bangsa atau ekonomi mungkin siap, bersedia atau siap untuk memperoleh manfaat yang muncul dari teknologi informasi dan komunikasi (TIK) (Tamperensis, n.d.). Kualitas layanan yang dikirim dan kepuasan para pemangku kepentingan dengan layanan seperti itu tergantung pada kematangan sistem e-Government. Karena karakteristik budaya mereka, negara yang berbeda dapat mengalami tingkat yang berbeda dari ruang lingkup dan kepadatan e-Government (yaitu, eGovernment readiness) (Khalil, 20II). Budaya organisasi adalah seperangkat nilai-nilai dan keyakinan yang mengakar dalam yang memberikan norma untuk perilaku

Dari factual problem yang telah dijabarkan diatas Sehingga dapat ditarik pertanyaan dalam penelitian ini adalah I. Kesiapan Penerapan Sistem Pemerintahan Berbasis Elektronik (SPBE) di BPPT sejauh mana? Dan 2. Upaya-upaya yang dapat dilakukan untuk mensukseskan SPBE di BPPT?

Sehingga pada jurnal ini penulis akan menganalisis mengenai kesiapan penerapan SPBE dalam inovasi digitalisasi layanan sistem administrasi di BPPT dan menganalisis upaya-upaya yang dilakukan organisasi untuk mempersiapkan Sumber Daya Manusia atau individu dalam organisasi untuk dalam menghadapi perubahan sistem administrasi perkantoran menjadi 
penerapan SPBE secara keseluruhan pada Badan Pengkajian dan Penerapan Teknologi.

Ronald Heifetz dalam bahasan teori organisasional (Starr \& Starr, 2019), yang menjelaskan bahwa perubahan bukan sebagai proses teknis, tetapi sebagai proses "adaptif", yaitu berkaitan dengan bagaimana individu -individu berkumpul untuk memecahkan masalah. Dalam sebuah perubahan dalam organisasi diperlukan kesiapan dari pegawai selaku anggota organisasi yaitu I. Keyakinan, 2. Sikap, 3. Niat (Achilles, Stanley, Relations, \& Oaks, 1993).

Teori yang digunakan dalam penelitian ini yaitu Teori Readiness to organizational change (Holt, Armenakis, Feild, \& Harris, 2007) yang diteliti dalam penelitian ini ada beberapa dimensi sebagai berikut :

Change - specific efficacy, organisasi mampu menerapkan perubahan. Dalam dimensi ini hal yang diukur seperti Ketersediaan Sumberdaya Manusia secara Kuantitatif dan Kualitatif, Ketersediaan Infrastruktur dan Software yang Memadai, Kemampuan Kerjasama Team, Biaya, Sosialisasi dan pelatihan.

Appropriateness, perubahan sesuai dengan organisasi. Dalam dimensi ini hal yang diukur seperti Kesesuaian Perubahan e-office atau SPBE dengan Kebutuhan Organisasi, Perencanaan yang baik, Perubahan sejalan dengan tugas dan fungsi Organisasi, Sarana dan Prasarana Memadai.

Management support, adanya dukungan dari pimpinan.

Dalam dimensi ini hal yang diukur seperti Dukungan pimpinan yaitu baik Pimpinan Ikut serta dalam berbagai sosialisasi, Pimpinan berkomitmen dan ikut menggunakan e-office.

Personal valence, memberikan keuntungan bagi pegawai.

Dalam dimensi ini hal yang diukur Keuntungan yang dirasakan Pegawai.
Tabel II. Operasionalisasi Konsep

\begin{tabular}{|c|c|c|c|}
\hline Konsep & Variabel & Dimensi & Indikator \\
\hline & & 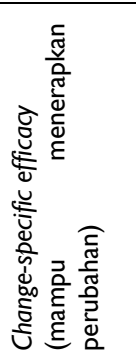 & $\begin{array}{ll}\text { I. } & \text { Ketersediaan } \\
& \text { Sumberdaya Manusia } \\
& \text { secara Kuantitatif dan } \\
\text { Kuantitatif } \\
\text { 2. }\end{array}$ \\
\hline 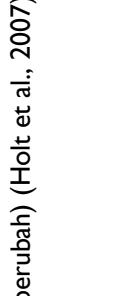 & 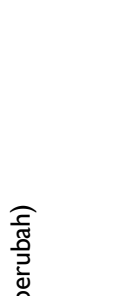 & 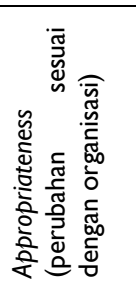 & 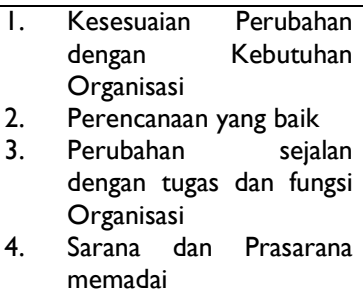 \\
\hline 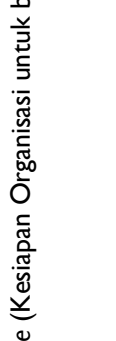 & 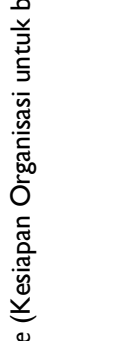 & 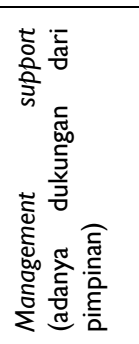 & $\begin{array}{l}\text { I. Dukungan Pimpinan Baik } \\
\text { 2. Pimpinan lkut serta atau } \\
\text { hadir dalam berbagai } \\
\text { acara sosialisasi } \\
\text { perubahan } \\
\text { 3. Pimpinan berkomitmen } \\
\text { dengan perubahan dan } \\
\text { ikut serta dalam } \\
\text { penggunaan perubahan }\end{array}$ \\
\hline 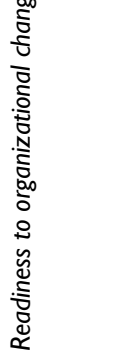 & 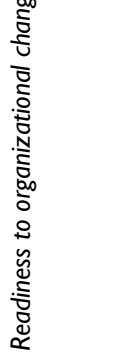 & 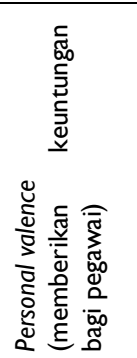 & $\begin{array}{l}\text { I. Ada tidaknya keuntungan } \\
\text { yang dirasakan oleh } \\
\text { pegawai }\end{array}$ \\
\hline
\end{tabular}

Sumber : Olah Data Pribadi, 2020

\section{METODOLOGI}

Pendekatan yang digunakan untuk penelitian ini adalah post-positivism dengan metode analisis deskriptif sebagai pendekatan dalam menghasilkan suatu pemahaman yang komprehensif dan mendalam terhadap fenomena yang ada. Jenis penelitian ini meneliti bagaimana fenomena dipahami oleh aktor yang relevan, dan bagaimana perbedaan pemahaman dan nilai-nilai ini dimainkan (Sharp et al., 2020). Teknik yang digunakan untuk mengumpulkan data untuk penelitian ini adalah wawancara mendalam, khususnya wawancara terstruktur di mana semua pertanyaan ditetapkan sebelum pelaksanaan wawancara. Informan kunci ini dipilih secara purposif yang artinya dengan secara 
khusus memilih informan - Informan tertentu berdasarkan ciri-ciri spesifik yang tidak dimiliki informan lainnya. terutama karena penulis telah menetapkan kriteria tentang informan yang dapat memberikan hasil penelitian yang diprediksi. Pertanyaan-pertanyaan penelitian yang diajukan dibagi menjadi dua kategori : pertama, kepada pimpinan atau tim perencana e-office; kedua, kategori pegawai. penulis menggunakan analisis post-positivism dengan pola pikir dari deduktif ke induktif yang maksudnya berangkat dari landasan teori umum sebagai alat untuk memotret peristiwa lalu kemudian teori tersebut dibawa kedalam temuan-temuan serta fenomena dilapangan untuk digali lebih dalam dengan analisis untuk mengeksplorasi seluruh makna dan nilai-nilai yang terkait dengan topik.

\section{HASIL DAN PEMBAHASAN}

\section{Kondisi Saat Ini}

Identifikasi kondisi saat ini bertujuan untuk memperoleh informasi yang memadai mengenai kondisi kesiapan implementasi SPBE yang ada saat ini di BPPT. Dari penelitian yang telah penulis lakukan, ditemukan bahwa BPPT sedang melakukan uji coba implementasi SPBE pada proses layanan administrasi internal. BPPT telah memiliki tata kelola TIK yang memadai yang terdiri dari tim pengarah/komite TIK dan Tim CIO, Rencana Induk, serta anggaran dan belanja TIK dimana kondisi tersebut juga didukung oleh Pimpinan BPPT dalam wujud dasar regulasi (Peraturan Kepala BPPT) sebagai dasar penggunaan aplikasi dan pedoman dalam melakukan Klasifikasi data dan informasi (informasi publik, informasi rahasia/terbatas). Dari sisi aplikasi BPPT telah melakukan melakukan pengembangan e-office melalui 4I digitalisasi layanan di lingkungan Sekretariat Utama BPPT.

Dari sisi Sumber Daya Manusia, BPPT sudah memiliki unit pengelola TIK yang tersertifikasi ISO
900I, dan juga dapat dikatakan bahwa pada dasarnya BPPT adalah Badan yang berkecimpung di bidang teknologi sehingga sebagian besar dari karyawan BPPT adalah sumber daya manusia yang berlatarbelakang pendidikan strata I (SI) dan lebih.
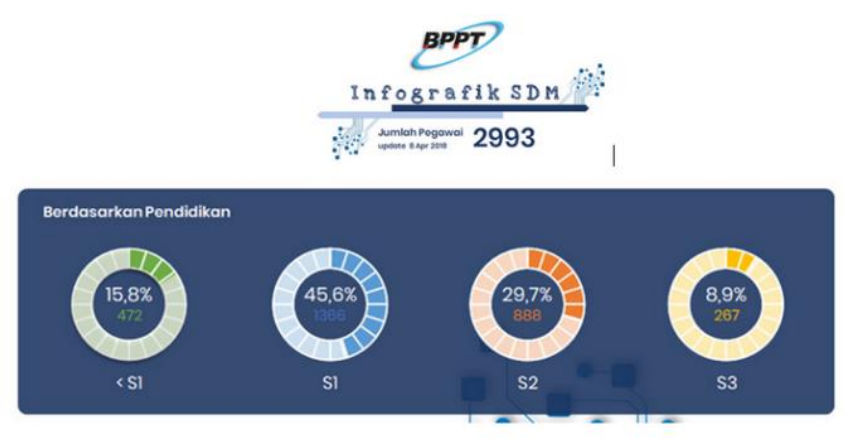

Grafik I. Prosentase Pegawai BPPT Berdasarkan Tingkat Pendidikan, Sumber : Biro SDMO BPPT 2019

Dari Grafik I dapat dilihat Prosentase Pegawai yang berpendidikan SI dan diatasnya lebih banyak dibandingkan dengan Prosentase Pegawai yang berlatarbelakang pendidikan dibawah SI. SDM BPPT saat ini juga menghadapi kendala masih banyaknya para pegawai yang tidak memahami sistem SPBE dan lebih memilih menggunakan sistem administrasi secara manual, hal ini terjadi karena kesenjangan digital dengan pemerataan pemahaman dan keterampilan para sumber daya manusia yang ada sangatlah minim. Disisi lain kesadaran keamanan informasi sebagian besar pegawai masih rendah sehingga seringkali berakibat pada serangan phishing dan infeksi virus atau malware.

Evaluasi SPBE terhadap pelaksanaan SPBE di BPPT telah dilakukan oleh Kementerian Pemberdayaan Aparatur Negara dan Reformasi Birokrasi (Kemenpan RB) untuk mengetahui capaian pelaksanaan SPBE melalui nilai indeks SPBE yang menggambarkan tingkat kematangan (maturity level) dari pelaksanaan SPBE. Penilaian pada pelaksanaan SPBE dilakukan melalui struktur yang terdiri dari domain, aspek, dan indikator. Indeks SPBE yang diperoleh BPPT sebesar 3,31 dengan 
detail nilai indeks untuk setiap domain sebagai berikut:

\begin{tabular}{|c|l|}
\hline \multicolumn{2}{|c|}{ Nabel III. Indeks SPBE BPPT 20I8 } \\
\hline SPBE Indeks & Nilai \\
\hline Domain Kebijakan SPBE & 3,31 \\
\hline Kebijakan Tata Kelola SPBE & 3,00 \\
\hline Kebijakan Layanan SPBE & 3,00 \\
\hline Domain Tata Kelola & 3,00 \\
\hline Kelembagaan & 3,29 \\
\hline Strategi \& Perencanaan & 2,50 \\
\hline TIK & 3,50 \\
\hline Domain Layanan SPBE & 3,67 \\
\hline Administrasi Pemerintahan & 3,57 \\
\hline Pelayanan Publik & 3,57 \\
\hline
\end{tabular}

Sumber : Kemenpan RB 2018

*atatan : nilai 5 maksimal

Dapat dilihat pada tabel diatas bahwa sistem SPBE di BPPT dapat dikatakan masih dalam tahap proses pembangunan dimana nilai indeks masih di bawah nilai ideal yaitu 4,00, terutama adapat dilihat dari Domain Tata Kelola indeks Kelembagaan yang masih sangat rendah yaitu 2,5 dimana nilai tersebut adalah setengah dari nilai maksimal yang ada. Kemudian BPPT masih memiliki banyak kekurangan terhadap SPBE itu sendiri yang dimulai dari belum tersedianya aturan dan standar kepemilikan data (wali data) sesuai dengan tugas pokok dan fungsi unit kerja karena belum adanya integrasi layanan naskah dinas secara elektronik, hal ini juga disebabkan oleh belum terintegrasinya proses bisnis antar unit kerja

Sedangkan terhadap sisi external masih banyak aplikasi yang belum menyediakan layanan kolaborasi melalui integrasi dengan layanan SPBE instansi lainnya dimana hal tersebut terjadi karena belum adanya regulasi atau SOP terkait integrasi sistem aplikasi dengan instansi lainnya.

\section{Analisis Kesenjangan (Gap Analysis)}

Gap Analysis atau Analisa kekosongan adalah salah satu strategi yang dapat dilaksanakan guna megidentifikasi kekosongan (gap) yang terjadi diantara kondisi saat ini dengan kondisi yang diharapkan yaitu kondisi implementasi SPBE yang sudah mendekati ideal untuk mendukung tugas fungsi BPPT terhadap pelayanan publik yang sesuai dengan teori SPBE menurut Indrajid (2006) yaitu Government to Citizen, Government to Business, Government to Employee, Government to Government. Analisis ini akan memberikan suatu gambaran terhadap kebutuhan aspek-aspek kesiapan BPPT untuk bertransformasi menuju ideal yang efektif, efisien, dan akuntabel. Dari gambaran aspek yang dibutuhkan dalam mencapai kondisi yang diharapkan pada 2024 dapat disusun kebijakankebijakan bagi setiap aspek untuk diterapkan mulai dari tahun 2020 hingga 2024 dengan suatu bentuk roadmap yang deilengkapi dengan action plan yang lebih detail.
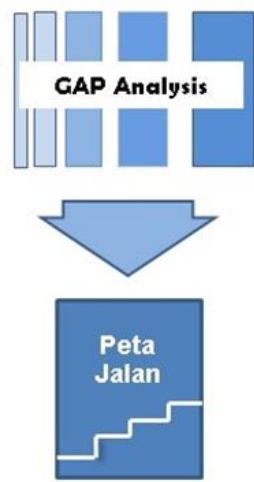

Gambar II: Diagram Metode Penyusunan Rencana Induk SPBE-BPPT

Kebijakan SPBE di BPPT saat ini belum semuanya di atur dengan kebijakan yang melandasi pengembangan dan operasionalnya. Namun tahun 2019 telah dibuat Peraturan Badan (Perban) Badan Pengkajian dan Penerapan Teknologi No. 24 Tahun 2019 tentang Kebijakan Sistem Pemerintahan Berbasis Elektronik BPPT serta Peraturan Kepala (Perka) Badan Pengkajian dan Penerapan Teknologi 
No. 05 Tahun 2019 Tentang Penerapan Sertifikat

Elektronik Pada BPPT sebagai pendukung keberlangsungan SPBE diBPPT. Satu persatu BPPT mengisi gap yang terjadi ditahun sebelumnya namun masih Dibutuhkan beberapa kebijakan lagi sebagai acuan payung hukum pengembangan SPBE agar layanan internal maupaun external dapat menjadi program prioritas SPBE BPPT.

\section{HASIL WAWANCARA}

Kesiapan adalah faktor penting dalam sebuah rencana implementasi perubahan proses administasi dari manual ke digital (e-office), Dikatakan Siap apabila hasil yang diperoleh semakin mendekati target yang telah ditetapkan. Semakin mendekati target, maka dapat dikatakan semakin Siap. untuk itu diperlukan pengukuran Kesiapan yang sesuai dengan sasaran dan tujuan yang hendak dicapai.

Guna menggali lebih dalam pembahasan mengenai kesiapan BPPT terhadap SPBE ini, maka penulis melakukan wawancara yang dilakukan dengan informan yang dinyatakan pada bagian metodologi. dan teori-teori yang ada terkait dengan topik yang akan dihubungkan Hasil dan evaluasi akan dieksplorasi dan dinyatakan secara eksplisit. Pada awalnya, dimensi dalam teori tersebut dieksplorasi sebagai hasil yang diberikan oleh informan. Pertanyaan untuk wawancara ditetapkan sebelum wawancara dilakukan. Semua hasil wawancara ditranskripsikan. Dimensi-dimensi tersebut difokuskan pada Change-specific efficacy (mampu menerapkan perubahan), Appropriateness (perubahan sesuai dengan organisasi), Management support (adanya dukungan dari pimpinan), Personal valence (memberikan keuntungan bagi pegawai)

\section{Change Spesific efficacy}

Berdasarkan wawancara yang penulis lakukan dengan beberapa Pimpinan terkait atau Tim Perencana SPBE dan pegawai BPPT, dapat dideskripsikan bahwa dari segi kualitas dan kuantitas SDM BPPT masih kekurangan orang untuk pengembangan aplikasi maupun integrasi namun dari sisi kualitas SDM cukup capable untuk melakukan perubahan administrasi ke digitalisasi layanan administrasi. Dari segi Infrastruktur dan software juga tidak terkendala karena selalu dipelihara dengan baik dan di update secara berkala, aplikasi-aplikasi juga sudah hampir siap semua baik yang dikembangkankan sendiri maupun dengan bantuan vendor. Dari Segi Kerjasama tim, BPPT juga telah memiliki daftar PIC untuk setiap unit kerja sebagai jembatan mengenai penerapan SPBE serta kerjasama lintas unit juga sudah tertera dalam beberapa aplikasi. Dari segi Biaya juga sebagian besar sudah dianggarkan ditahun sebelumnya dan untuk kekurangannya bisa diatasi dengan tambahan dana lain. Dari Segi sosialisasi dan pelatihan BPPT juga sudah mulai mensosialisasikan secara bertahap satu persatu aplikasi yang baru diluncurkan dan tentunya ada pelatihan untuk semua karyawan baik yang terbiasa maupun yang tidak terbiasa menggunakan aplikasi, akan tetapi dari hasil wawancara ditemukenali bahwa proses sosialisasi belum maksimal karena tidak meratanya informasi bagi masing-masing unit itu sendiri serta terbatasnya biaya untuk sosialisasi. Dari serangkaian pendapat diatas dapat disimpulkan bahwa BPPT sudah Siap dan mampu menerapkan perubahan digitalisasi SPBE pada sistim administrasi pekerjaan.

\section{Appropriateness}

Penelitian sebelumnya telah menyarankan bahwa penyelarasan Teknologi Informasi dengan tujuan organisasi adalah faktor yang mempengaruhi keberhasilan e-government (Al-Bulushi, 20I7). Berdasarkan wawancara yang penulis lakukan dengan beberapa pimpinan atau Tim Perencana SPBE dan pegawai BPPT, dapat diketahui bahwa terdapat Kesesuaian Perubahan e-office atau SPBE 
dengan Kebutuhan Organisasi karena sejalan dengan tugas dan fungsi BPPT juga tagline yang dibuat Kepala PPT namun untuk memenuhi semua kebutuhan digitalissi masih perlu pengembangan dan rencana lebih lanjut. Dari segi Perencanaan saat ini semua diyakini sudah diatas $80 \%$ kesiapannya sesuai dengan yang direncanakan, dari segi apakah Perubahan sejalan dengan tugas dan fungsi Organisasi hal ini sejalan dengan apa yang dibutuhkan oleh organisasi BPPT karena sesungguhnya aplikasi ini hanyalah tools untuk membantu tugas dan fungsi BPPT. Dari segi Sarana dan Prasarana diyakini sudah cukup memadai untuk keberhasilan penerapan SPBE di BPPT.

\section{Management support}

Penelitian sebelumnya pernah membahas bahwa pemimpin yang telah mengambil tindakan mengartikulasikan dan mempromosikan penerimaan visi dan strategi, atau memfasilitasi pengiriman layanan elektronik dan penerapan struktur secara efektif dapat mengarah pada kesuksesan proses layanan e-government (Ching \& Luk, 2009). Berdasarkan wawancara yang penulis lakukan dengan beberapa pimpinan terkait atau tim perencana SPBE dan pegawai BPPT, dapat dianalisis bahwa dari segi dukungan pimpinan puncak dalam hal ini Kepala BPPT sangat baik terhadap perubahan ini, bahkan Kepala BPPT lkut serta dalam mensosialisasikan aplikasi-aplikasi e-office tersebut diberbagai kesempatan, hal itu menunjukkan bahwa Kepala BPPT dan jajaran pimpinan lainnya memiliki komitmen yang tinggi dan juga dari segi penggunaan aplikasi pimpinan tertinggi di BPPT juga ikut menggunakan e-office dalam pekerjaannya seharihari. Dapat disimpulkan bahwa adanya dukungan dari pimpinan tertinggi BPPT sangat baik terhadap perubahan yang direncanakan .

\section{Personal Valence}

Pernah ada penelitian menunjukkan bahwa ketiga dimensi kualitas (yaitu kualitas kualitas sistem, kualitas informasi, kualitas layanan memiliki dampak positif pada niat pegawai untuk menggunakan, Keberhasilan ini juga mendukung anggapan bahwa kualitas layanan yang baik mendorong pemanfaatan Teknologi Informasi yang lebih baik dan menciptakan banyak manfaat bagi organisasi (Culibrk, Lalic, Stefanovic, Marjanovic, \& Delic, 2016). Begitu pula berdasarkan wawancara yang penulis lakukan dengan beberapa pimpinan terkait atau tim perencana SPBE dan pegawai BPPT, dapat diketahui dari sisi pimpinan dan tim SPBE merasa banyak hal yang diuntungkan dengan perubahan digitalisasi ini, dan dari sisi pegawai juga menyatakan banyak keuntungan yang mereka rasakan secara pribadi terhadap kemudahan yang diberikan oleh kualitas layanan dalam pekerjaannya walaupun diawalnya terasa sedikit sulit. Dari hal tersebut dapat disimpulkan bahwa e-office atau digitalisasi administrasi memberikan banyak manfaat bagi pegawai.

Dari hasil wawancara tersebut dapat terlihat bahwa dimensi Appropriateness, Management support, serta Personal valence sudah sangat sesuai dengan kesiapan BPPT terhadap SPBE, hanya I dimensi yang masih belum sesuai terhadap kesiapan BPPT itu sendiri yaitu Change Spesific efficacy. Maka berdasarkan dimensi Change Spesific efficacy tersebutlah penulis akan menitik beratkan penielitian ini dimana Change Spesific efficacy memiliki komponen kualitas serta kuantitas SDM, Infrastruktur dan Software, kerjasama tim, biaya, dan sosialisasi. Berdasarkan kumpulan data dari hasil wawancara penulis menuangkan kedalam grafik sebagai berikut : 


\section{Kesiapan SDM}

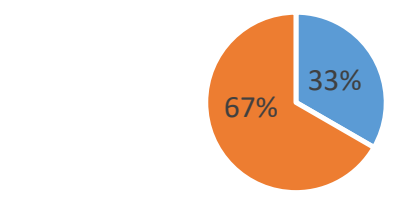

- Menyatakan Kurang - Menyatakan Cukup

Grafik II. Kesiapan SDM

Kuantitas SDM yang siap dalam penerapan SPBE hanya $67 \%$ dari total keseluruhan yang ada, hal ini dirasa sangat kurang, karena SPBE akan di terapkan kepada keseluruhan organisasi BPPT itu sendiri. Dukungan pengembangan dan implementasi SPBE di BPPT hanya dapat dilakukan apabila tersedia SDM yang memadai dan internalisasi budaya kerja berbasis TIK. Dalam menghadapi era transformasi digital, SDM yang memiliki budaya kerja berbasis TIK merupakan salah satu hal penting yang harus diperhatikan. Untuk itu, pengembangan SDM SPBE harus dilakukan dan dapat tercapai dengan eskalasi pengetahuan serta imepelementasi SPBE dengan praktik terbaik, SPBE yang dibangun berdasarkan budaya kerja yang baik, jabatan fungsional Pegawai Negeri Sipil yang ditingkatkan, serta melaakukan kemitraan dengan pihak-pihak yang terkait.

\section{Sosialisasi}

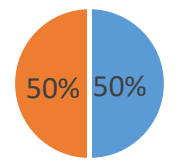

- Menyatakan Kurang Menyatakan Cukup

\section{Grafik III. Sosialisasi}

Untuk komponen sosialisasi $50 \%$ dari informan menyatakan bahwa sosialisai SPBE belum cukup di sosialisasikan terhadap pegawai BPPT sehingg besar kemungkinan terjadi kelasahan dalam persepsi serta tata cara SPBE yang sesuai standar.

Inovasi penerapan TIK dalam bentuk sistem pemerintahan berbasis elektronik memberikan peluang untuk mewujudkan arah kebijakan dan strategi tersebut dalam rangka menghasilkan sistem pengawasan, sistem administrasi pemerintahan, dan pelayanan publik yang lebih cepat, lebih baik, dan lebih murah.

\section{KONDISI YANG DIHARAPKAN}

SPBE BPPT diharapkan dapat menjadi bagian utama pendorong keberhasilan BPPT dalam mencapai rencana strategisnya. Hal ini dapat terlaksana dengan melaksanakan upaya-upaya pengembangan dan penerapan teknologi informasi dan komunikasi terkini yang tepat guna dan tepat sasaran. Pengembangan dan implementasi teknologi informasi dan komunikasi dalam rangka membangun SPBE BPPT juga harus berdasarkan peraturan yang ada, terutama Peraturan Pemerintah tentang SPBE yang dalam implementasinya dapat diukur dalam indeks SPBE sebagai indikasi keberhasilan pengembangan dan penerapannya dalam instansi pemerintah.

Tabel IV. Nilai Indeks SPBE BPPT Yang Diharapkan

\begin{tabular}{|l|c|c|c|c|c|c|c|}
\hline \multirow{2}{*}{$\begin{array}{l}\text { Nilai } \\
\text { Indeks }\end{array}$} & $\begin{array}{c}\text { Kondisi } \\
\text { Saat Ini } \\
\mathbf{( 2 0 1 8 )}\end{array}$ & \multicolumn{6}{|c|}{ Kondisi Yang Diinginkan } \\
\cline { 3 - 8 } & $\mathbf{2 0 1 9}$ & $\mathbf{2 0 2 0}$ & $\mathbf{2 0 2 1}$ & $\mathbf{2 0 2 2}$ & $\mathbf{2 0 2 3}$ & $\mathbf{2 0 2 4}$ \\
\hline SPBE & $\mathbf{3 , 3 1}$ & $\mathbf{4 , 0 1}$ & $\mathbf{4 , 2 4}$ & $\mathbf{4 , 6 0}$ & $\mathbf{4 , 6 8}$ & $\mathbf{4 , 8 1}$ & $\mathbf{4 , 9 3}$ \\
\hline $\begin{array}{l}\text { Domain } \\
\text { Kebijakan } \\
\text { SPBE }\end{array}$ & $\mathbf{3 , 0 0}$ & $\mathbf{3 , 7 1}$ & $\mathbf{4 , 3 5}$ & $\mathbf{4 , 7 6}$ & $\mathbf{4 , 9 4}$ & $\mathbf{4 , 9 4}$ & $\mathbf{5 , 0 0}$ \\
\hline $\begin{array}{l}\text { Kebijakan } \\
\text { Tata } \\
\text { Kelola } \\
\text { SPBE }\end{array}$ & 3,00 & 3,57 & 4,14 & 4,71 & 5,00 & 5,00 & 5,00 \\
\hline $\begin{array}{l}\text { Kebijakan } \\
\text { Layanan } \\
\text { SPBE }\end{array}$ & 3,00 & 3,80 & 4,50 & 4,80 & 4,90 & 4,90 & 5,00 \\
\hline $\begin{array}{l}\text { Domain } \\
\text { Tata } \\
\text { Kelola }\end{array}$ & $\mathbf{3 , 2 9}$ & $\mathbf{3 , 8 6}$ & $\mathbf{4 , 2 9}$ & $\mathbf{4 , 7 1}$ & $\mathbf{4 , 7 1}$ & $\mathbf{4 , 7}$ & $\mathbf{5 , 0 0}$ \\
\hline
\end{tabular}




\begin{tabular}{|l|c|c|c|c|c|c|c|}
\hline $\begin{array}{l}\text { Kelembag } \\
\text { aan }\end{array}$ & 2,50 & 3,50 & 4,00 & 5,00 & 5,00 & 5,00 & 5,00 \\
\hline $\begin{array}{l}\text { Strategi \& } \\
\text { Perencan } \\
\text { aan }\end{array}$ & 3,50 & 4,00 & 4,00 & 4,00 & 4,00 & 4,00 & 5,00 \\
\hline TIK & 3,67 & 4,00 & 4,67 & 5,00 & 5,00 & 5,00 & 5,00 \\
\hline $\begin{array}{l}\text { Domain } \\
\text { Layanan } \\
\text { SPBE }\end{array}$ & $\mathbf{3 , 4 2}$ & $\mathbf{4 , 1 8}$ & $\mathbf{4 , 1 8}$ & $\mathbf{4 , 4 8}$ & $\mathbf{4 , 5 8}$ & $\mathbf{4 , 8 2}$ & $\mathbf{4 , 8 8}$ \\
\hline $\begin{array}{l}\text { Administr } \\
\text { asi } \\
\text { Pemerinta } \\
\text { han }\end{array}$ & 3,57 & 4,57 & 4,57 & 4,86 & 5,00 & 5,00 & 5,00 \\
\hline $\begin{array}{l}\text { Pelayanan } \\
\text { Publik }\end{array}$ & 3,17 & 3,50 & 3,50 & 3,83 & 3,83 & 4,50 & 4,67 \\
\hline
\end{tabular}

Sumber : CIO BPPT 2019

Dari tabel diatas terlihat bahwa BPPT sudah menyiapkan roadmap seampai dengan 2024 untuk menuju kearah SPBE yang sempurna dengan ukuran indeks maksimum.

\section{STRATEGI}

Untuk mewujudkan SPBE yang terpadu dan menyeluruh, Tata Kelola SPBE dapat dilakukan dengan penguatan kapasitas pengelolaan dan sistem koordinasi pelaksanaan SPBE dan kebijakan SPBE. Perbaikan tatakelola dapat dicapai melalui pembentukan tim koordinasi SPBE di BPPT dengan didukung oleh ketersediaan peta proses bisnis dari pimpinan tertinggi sampai dengan unit kerja. Tata Kelola SPBE juga merupakan kerangka kerja yang memastikan terlaksananya pengaturan, pengarahan, dan pengendalian dalam penerapan SPBE secara terpadu dan meliputi setidaknya 4 (empat) aspek yaitu:

\section{Kebijakan}

Kebijakan diarahkan untuk melibatkan semua pemangku kepentingan di dalam perumusan dan pelaksanaan kebijakan SPBE yang mencakup kebijakan makro, meso, dan mikro. Perumusan dan pelaksanaan dilakukan dengan berkoordinasi dengan Tim Koordinasi SPBE
BPPT sehingga menciptakan kebijakan SPBE yang terpadu.

2. Kelembagaan

Pembentukan dan penguatan Tim Koordinasi SPBE serta pengaturan tugas - tugas yang mendukung penerapan SPBE baik di internal BPPT maupun antar instansi.

3. Percepatan Integrasi

Melakukan pengembangan bertahap, percepatan integrasi semua aplikasi agar memaksimalkan pemanfaatannya, dan implementasi secara serempak.

4. Anggaran dan Belanja

Pemanfaatan anggaran yang optimal merupakan salah satu upaya untuk mewujudkan SPBE yang terpadu.

5. Sosialisasi

Sosialisasi SPBE melalui bimbingan teknis secara merata terhadap semua pegawai BPPT.

6. Monitoring dan Evaluasi

Monitoring dan Evaluasi bertujuan untuk mengetahui capaian kemajuan pelaksanaan SPBE dan memberikan saran perbaikan untuk peningkatan kualitas pelaksanaan SPBE. Evaluasi dilakukan oleh Tim Koordinasi SPBE secara periodik dan mandiri.

\section{KESIMPULAN}

Penerapan e-office di BPPT saat ini belum dapat diterapkan secara ideal karena aplikasi-aplikasi yang direncanakan tersebut belum sepenuhnya diterapkan dan belum diuji coba secara keseluruhan. Antara aplikasi-aplikasi e-office yang menjadi portal utama yang menaungi atau memayungi aplikasi-aplikasi lain yang sudah berjalan yang dapat digunakan oleh dan untuk seluruh pegawai BPPT juga belum terintegrasi. SPBE BPPT diarahkan agar dapat menerapkan transformasi digital dalam keseluruhan proses bisnis di BPPT dalam rangka mewujudkan Visi, Misi, dan Peran 
BPPT hingga tahun 2024, sehingga BPPT dapat menjadi lembaga yang Solid Smart Speed dalam tata kelola pemerintahan guna mencapai birokrasi pemerintahan secara terpadu dengan memiliki kinerja tinggi, kualitas pelayanan publik yang lebih meningkat, Menciptakan penyelenggaraan pemerintahan yang efektif, efisien, transparan, dan akuntabel, dimana pada akhirnya dapat terwujudkan sebagai bangsa yang memikili daya saing.

Saran yang dapat penulis berikan semua rencana tersebut dapat terealisasi dengan dukungan penuh Pimpinan, Manajemen, dan seluruh stakeholder BPPT, disertai dengan pendanaan yang memadai, dan menjalankan strategi yang telah direncanakan. Alokasi anggaran dan belanja TIK harus menjadi salah satu prioritas agar pengembangan dan implementasi SPBE berjalan baik dengan sedapat mungkin mendekati praktek terbaik. Perlu penelitian lebih lanjut dan lebih mendalam mengenai kesiapan perubahan e-office dilihat dari lebih banyak dimensi penelitian.

\section{REFERENSI}

Achilles, A., Stanley, G., Relations, K. W. H., \& Oaks, T. (1993). Creating readiness for organizational change. 46(Jun), I-I5.

Aziz, N. M. (2010). E-Readiness Model: A Comparative Review. (2008).

Ching, S., \& Luk, Y. (2009). The impact of leadership and stakeholders on the success / failure of egovernment service: Using the case study of estamping service in Hong Kong. Government Information Quarterly, 26(4), 594-604. https://doi.org/10.1016/j.giq.2009.02.009

Culibrk, D., Lalic, B., Stefanovic, D., Marjanovic, U., \& Delic, M. (2016). Information \& Management Assessing the success of e-government systems: An employee perspective. 53, 717-726. https://doi.org//0.1016/j.im.2016.02.007

Evans, D., \& Yen, D. C. (2006). E-Government: Evolving relationship of citizens and government, domestic, and international development. 23, 207-235. https://doi.org/10.1016/j.giq.2005.1 I.004

Holt, D. T., Armenakis, A. A., Feild, H. S., \& Harris, S.
G. (2007). Readiness for organizational change: The systematic development of a scale. Journal of Applied Behavioral Science, 43(2), 232-255. https://doi.org// 0.1 I77/0021886306295295

Indrajit Richardus Eko. (2006) Elektronik Government : Konsep Pelayanan Publik Berbasis Internet dan Teknologi Informasi, Aptikom.

John P. Kotter (1996). Leading Change. Harvard Business School Press : Boston, Massachusetts. Printed in the united states of Amerika.

Khalil, O. E. M. (20II). e-Government readiness: Does national culture matter? $\downarrow$. Government Information Quarterly, 28(3), 388-399. https://doi.org/10.1016/j.giq.2010.06.01 I

Li, L., \& Dai, H. (20I I). Building a Change Management Model for E-Government Services Evolution. 20II Fifth International Conference on Management of E-Commerce and e-Government, 87-92. https://doi.org//0.1 I09/ICMeCG.201 I.40

Sharp, L., Mcdonald, A., Sim, P., Knamiller, C., Sefton, C., Wong, S., ... Wong, S. (2020). paradigmatic divide Positivism , post-positivism and domestic water demand: interrelating science across the paradigmatic divide. 36(4).

Starr, J. P., \& Starr, B. J. P. (2019). Organizing for for adaptive adaptive change man Organizing change manag. 98(8), 70-7I.

Stewart J and Kringas P (2003) Change managementstrategy and values in six agencies from the Australian Public Service.

Tamperensis, A. U. (n.d.). E-readiness of Public Administration in Developing Countries A case study on.

THE EFFECTS OF LEADERSHIP ROLES ON EGOVERNMENT PERFORMANCE IN OMAN by Yaqoob Dur Mohammed Al-Bulushi Copyright 2017 A Dissertation Presented in Partial Fulfillment of the Requirements for the Degree Doctor of Management in Organizational Leadership with a Specialization in Information Systems and Technology University of Phoenix. (2017).

\section{Peraturan Perundang-undangan :}

Undang-Undang Nomor I4 Tahun 2008 tentang Keterbukaan Informasi Publik

Peraturan Presiden RI Nomor 95 Tahun 2018 Tentang Sistem Pemerintahan Berbasis Elektronik 
Pinggar Hawa, Roy Valiant Salomo. 2020. Readiness of Digitalization Services for Electronic-Based Government Systems in Agency for the Assessment and Application of Technology (BPPT)

Peraturan Badan (Perban) Badan Pengkajian dan Penerapan Teknologi No.24 Tahun 2019 tentang Kebijakan Sistem Pemerintahan Berbasis Elektronik BPPT

Peraturan Kepala (Perka) Badan Pengkajian dan Penerapan Teknologi No. 05 Tahun 2019 Tentang Penerapan Sertifikat Elektronik Pada BPPT 